\title{
Cervical abrasion injuries in current dentistry
}

\begin{abstract}
Currently, dental abrasion is a frequent pathological condition, hence the importance of its study; to be specific, the cervical abrasion injury is the wear of the hard tissues of the tooth located in the neck of the tooth, produced by a constant frictional mechanical process. Clinically, at the beginning it is small horizontal groove near the cementenamel junction; However, then the walls form a wedge with polished, glassy surfaces and tactile sensitivity. This type of lesions usually have a multi-causal origin, where the oral hygiene technique should be supervised and corrected as part of the treatment, emphasizing the type, quantity and frequency of toothpaste use, hardness of brush and the pressure exerted during dental brushing. In this way, the correct diagnosis allows the professional to identify the possible causes and the specific treatment for each case.
\end{abstract}

Keywords: cervical lesion, dental abrasion, mechanical frictional wear, dental neck
Volume 9 Issue 2 - 2018

\author{
Alejandro J Amaíz Flores \\ General Dentist, Specialist in Operative and Aesthetic \\ Odontology, Central University of Venezuela, Venezuela \\ Correspondence: Alejandro Amaíz Flores, General Dentist, \\ Specialist in Operative and Aesthetic Odontology, Central \\ University of Venezuela (U.C.V.), with validation of foreign \\ degrees at the University of Costa Rica, Periodontics at the \\ University of Costa Rica, Costa Rica, Tel 84547265, \\ Email alejandro.amaiz@gmail.com
}

Received: March 7, 2018| Published: April 19, 2018

\section{Introduction}

In this era the longevity of the population has increased, which is combined with the greater conservation of teeth in the mouth of the patients. Likewise, the incidence of cavities and cervical lesions has also increased simultaneously, does not make any sense. In modern dental practices, patients may present various forms of dental wear, which can be presented as cavities, abfraction, abrasion, attrition or erosion, ${ }^{1}$ particularly in the lesions on the cervical third regions, may have a microbial origin, associated with dental caries and a nonmicrobial or non-carious origin, where abrasion injuries are included. Multiple studies have shown the prevalence and continuous increase of dental abrasion injuries worldwide. Therefore, the objective of this article is to provide updated knowledge of this type of injuries to facilitate diagnosis, promote prevention and decide the most appropriate treatment plan for each case; so, his specific objectives of this article are:

1. Inquire about the etiological agents of abrasion injuries.

2. Explore the clinical characteristics of abrasion injuries.

3. Examine possible treatments for abrasion injuries.

Likewise, it is intended to illustrate said informations with photographs of clinical cases; where, the methodology used was a detailed investigation of the international literature, both in books and in scientific studies found in the main databases (Sciencedirect, Pubmed, Ebsco and Redalyc.org), considering the articles linked to the objectives of the study.

\section{Development}

The term abrasion is derived from the latin verb abrasum and describes the dental pathology that consists of the wear of the hard tissues of the tooth, through a frictional mechanical process ${ }^{2-4}$ to repeated contact with different objects, different from the teeth. In this way, abrasion is defined as a pathological process caused by abrasive substances on the tooth surface or any object placed repeatedly between or on the teeth. ${ }^{1,2}$ In Europe, research has reported different forms of abrasion in prehistoric populations, dental samples recovered from the Pleistocene in Spain show interproximal grooves between the posterior teeth; these grooves were only found in adults and were apparently caused by the use of interdental objects such as prehistoric toothpicks, where particles in the diet probably influenced this abrasive phenomenon. In the same way, this same condition is observed in current societies, where other articles can generate abrasion injuries on the teeth, namely: pipes (smokers), musical instruments, pins or needles, pens and pencils ${ }^{1}$ (Figure 1).

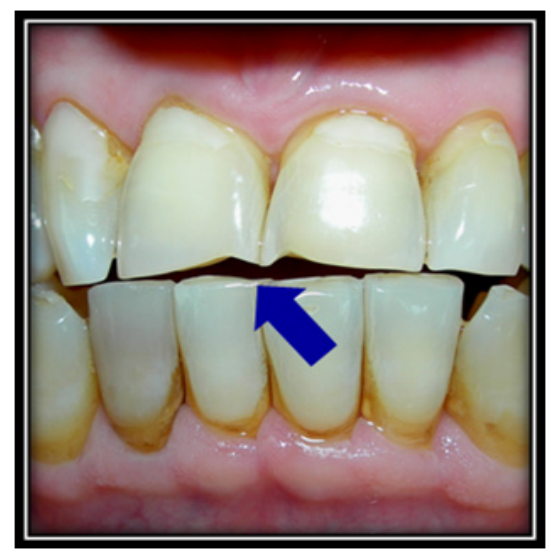

Figure I Female patient, 47 years old, seamstress by trade, at the clinical examination shows dental abrasion lesions, located on the incisal edges of both upper central incisors, produced by the repeated interposition of pins and needles. Photograph courtesy of the author.

However, in cervical abrasion injuries wear is located in the neck of the tooth specifically in the cervical third, being able to encompass the proximal, vestibular, lingual or palatal surfaces of the teeth, ${ }^{5-8}$ commonly in canines and premolars. ${ }^{9}$ Epidemiologically, the high incidence of cervical lesions is the result of certain morphological alterations and histological characteristics of this area, where the crown of the tooth becomes more vulnerable to physical and chemical stimuli due to the gradual reduction of the enamel thickness towards the cemento-enamel junction and to the density of the enamel surface near the dentino-enamel junction. In addition, the strength of the enamel in the cervical third is less due to the direction of the dental rods, which become flat. ${ }^{9}$ Clinically, the cervical abrasion in its initial 
state is observed as a small horizontal groove near of the cementenamel junction on the vestibular surface of the crown of the tooth (Figure 2), it also presents a polished surface with a glassy appearance and tactile sensitivity to the path of the explorer.,10

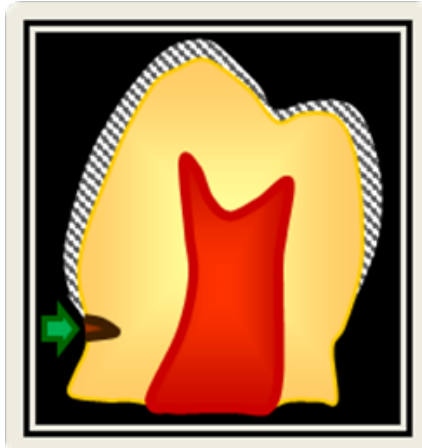

Figure 2 Schematic drawing of a dental abrasion cervical lesion, in its initial state. Courtesy of the author

However, with the advancement of the lesion, the walls constitute a "V" shape or wedge (cuneiform defect) with an acute axial angle, forming an angle close to $90^{\circ}$, with a depth that can oscillate between 1 and $2 \mathrm{~mm}$, (Figure 3) although in exceptional cases lesions can be seen up to $4 \mathrm{~mm}$ deep, with possible pulpal exposure. ${ }^{7,10}$ In most of the cases, the surfaces of these lesions are observed hard, smooth and bright, with sharp edges and a characteristic transparency, which is derived from precipitated crystals of beta tricalcium phosphate substituted with $\mathrm{Mg} \backslash$ Beta-TCMP. In addition, these defects can also be found on the interproximal surfaces of the lower incisors, due to improper and excessive use of dental floss. ${ }^{9}$

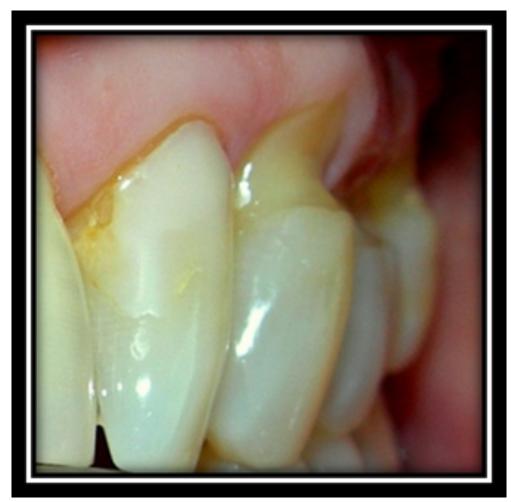

Figure 3 The same patient also presents on the vestibular surface of the right upper lateral incisor (7) a class $V$ cervical restoration of old composite resin, which is fractured with superficial deterioration. In addition, a combined cervical lesion of erosion and dental abrasion is observed on the vestibular surface of the right upper canine (6), accompanied by an apical migration of the gingiva. Photograph courtesy of the author.

At present, there are several indexes or classification systems for this type of injuries, unfortunately due to the lack of uniformity between them it is not possible to adequately reflect the morphological characterization, which makes it difficult to report cases and the comparison between the different injuries; In addition, clinically most of the proposed indices are not sensitive enough for severe changes in the wear of the teeth involved. ${ }^{11}$ Therefore, it is necessary to develop a classification system that facilitates the assessment and describes in detail the condition of these injuries, quantifying the severity of them, using little time for the professional. Likewise, a comfortable index of understanding and use is required to guide the most appropriate therapeutic measures for each case. ${ }^{11}$ From the etiological point of view, this type of cervical wear can be a universal consequence linked to aging, where a combination of pathologies coexist: erosion, abrasion and abfraction ${ }^{12}$ therefore, it is established that this type of lesions usually have a multi-causal origin, in which several factors intervene, directly and indirectly, which tend to be constant, such as aggressive tooth brushing or incorrect brushing technique; which determines the appearance and development of such cervical lesions on the vestibular surfaces of the teeth of the left quadrant for righthanded patients and in the right quadrant for left-handed patients, being the canines the teeth most affected by their prominence inside the arcade. ${ }^{2}$ Similarly, it is also important to assess the motivation and routine of oral hygiene of the patient, in terms of the type of toothpaste, the place where the toothbrush is started, the number of times the toothpaste is applied, the hardness of the bristles of the brush, the frequency and the pressure applied during brushing, because all these variables can affect the etiology of cervical abrasion injuries and the premature wear of dental restorations ${ }^{2}$ Estefan et al. ${ }^{13}$. Abrasion has been investigated in the laboratory and clinically, where most of the studies have been based on the hypothesis of brushing with abrasive toothpastes. However, recent studies reveal clinically insignificant values in enamel, while investigations in dentin are scarce and inconclusive due to the complexity of this tissue and the difficulty of measuring and quantifying the results obtained. ${ }^{12}$ In this way, from these studies, horizontal brushing was suggested as an etiological agent that increases wear two or three times compared to vertical brushing. ${ }^{12}$ Therefore, vigorous brushing and the use of a highly abrasive toothpaste may be the most common factors in cervical abrasion injuries ${ }^{14}$ where, an alternative to control these injuries is the use of electric brushes that contain a sensor that alerts the user when it exceeds the limit of the force allowed. ${ }^{3}$

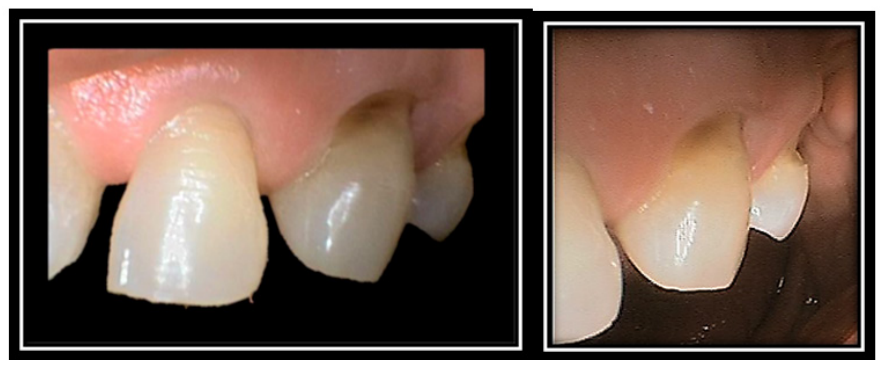

Figure 4 Male patients, 54 years old, who performs horizontal tooth brushing with excessive force. Clinically, it presents an initial abrasion lesion on the vestibular surface of the upper left lateral incisor (I0) in the form of horizontal grooves. In addition, on the vestibular surface of the left upper canine (II) and of the first upper left premolar (12) there are cervical lesions of dental abrasion with the formation of restorative dentine. Photograph courtesy of the author.

It should also be noted that tooth brushing could increase cervical abrasion if there are acid substances in the oral environment; where, the erosive agents promote the demineralization of the tooth and facilitate the wear of the tissues, therefore after exposure to acidic foods or gastric fluids should be avoided tooth brushing for at least 1 hour. ${ }^{15}$ For another part, in vitro investigations determined that brush bristles vary in their ability to transport abrasive dentifrices to the 
tooth structure, where hard bristles can cause less wear, while soft bristles can cause greater tooth abrasion. This is explained by the increase in the retention of the dentifrice to the smaller diameter of the filament, to denser plumes and to a greater flexion of the filament, increasing the contact area with the tooth surface during brushing. However, in vivo studies are necessary to corroborate this findings. ${ }^{3}$

The main treatment of abrasion injuries lies in prevention, which should include:

Education about the correct implementation of the oral hygiene techniques,

1. Change of risk or predisposing habits

2. Control of systemic diseases

3. Preventive measures for biological factors

4. Preventive measures for the chemical and physical agents involved. ${ }^{9}$

In this way, the treatment of these lesions can be both conservative and invasive. The non-invasive treatment (conservative) is based on recommendations or individualized instructions to the patient, aimed at: dietary advice, the decrease in the frequency of consumption of certain beverages and foods, the control of parafunctional habits, the instruction of correct hygiene measures oral, the use of rinses and fluorinated products, coupled with possible reconstructive procedures of periodontal nature. ${ }^{16,17}$ However, when conservative treatment is insufficient and cervical injury compromises the function and aesthetics of the tooth, the restoration of the lesion is necessary; which can be made with various materials of direct use, such as: dental amalgam, conventional ionomeric glass, resin-modified ionomeric glass, composite resin modified with ionomeric glass and composite resin ${ }^{7,18-20}$. In the present, the most common treatment for these injuries is restoration with composite resin. Therefore, it is also important to consider the impact of abrasion factors on this type of material in the cervical third. In fact, De Moraes and collaborators recorded an average loss of $1 \%$ in composite resins, related to the long-term alteration of the fill, where the nanohybrid and microhybrid composites showed similar results, showing lower roughness and loss of material. However, the effects of variations in $\mathrm{pH}$ and temperature, the presence of plasticizing agents, mechanical fatigue and the interaction of other stresses were not considered in this study and could have an impact on the clinical situation; other investigations are necessary in this regard. ${ }^{21}$ Therefore, the dentist must analyze in detail the particular characteristics inherent to the patient and the properties of each restorative material, to select the most appropriate for each case. $^{7,18,19}$

\section{Conclusion}

Currently, cervical abrasion injury is usually a frequent condition, which consists of damage or detriment caused by a continuous frictional mechanical process ${ }^{5,8}$ where, considering the possible etiologic agents involved, it is difficult to find these lesions as independent entities, due to the fact that in the majority of cases they occur jointly with abfraction and dental erosion..$^{2,7}$ In this way, the correct diagnosis of dental abrasion allows the professional to identify the possible causes that affect the formation of this pathology; likewise, it allows you to indicate the preventive treatment aimed at controlling the etiological agents and prevent the progress of the lesion or the invasive treatment with the most indicated restorative material. At all times, the professional must correct and supervise the oral hygiene technique of the patient as part of the treatment of these injuries, with emphasis on the type, amount and frequency of use of the toothpaste, the hardness of the brush bristles and the pressure exerted in tooth brushing, among other variables. $^{2-5}$

\section{Acknowledgment}

None.

\section{Conflict of interest}

None.

\section{References}

1. Curtis J, Farley B, Goldstein R. Chapter 17: Abfraction, abrasion, attrition, and erosion. In: Esthetics in Dentistry, People's Medical Publishing House USA Ltd (PMPH);2002:501-523.

2. Yap A, Neo J. Non-carious cervical tooth loss, Part 1. Dental Update. 1995;22(8):315-8.

3. Litonjua L, Andreana S, Bush P, et al. Tooth wear: Attrition, erosion, and abrasion. Quintessence Int. 2003;34(6):435-443.

4. Jiménez G. Aesthetic restorations of class V. In: Barrancos J, editor Operative Dental. 3rd ed, Buenos Aires: Editorial Panamericana Medical;2002:849-850.

5. Lanata E. Restorations of Class V of Black or Mount III. In: Lanata E, editor. Operative Dental. Aesthetics and adhesion. Buenos Aires: Grupo Guía S.A;2005:137-150

6. Lanata E, Chiappara B. Nomenclature and classification of the cavities. In Lanata E, editor. Operative Dental. Aesthetics and adhesion. Buenos Aires: Grupo Guía S.A;2005:33-38

7. Barrancos J, Barrancos G. General principles of preparations. In: Barrancos J , editor, Operative Dental. 3rd ed, Buenos Aires: Editorial Panamericana Medical;2002:471-534.

8. Barrancos J, Rodríguez G. Cariology. In: Barrancos J, editor, Operative Dental. 3rd ed, Buenos Aires: Editorial Panamericana Medical;2002:239-280.

9. Krolo M, Kovačević A. Noncarious Cervical Lessions: From Etiology to Therapy. Smile Dental Journal. 2015;10(1):22-26.

10. Garonne W. Cervical lesions and dentin hypersensitivity. Caries Res 1990;32(1):22-5.

11. Sawai MA. An easy classification for dental cervical abrasions. Dental Hypotheses. 2014;5(4):142-145.

12. Bartlett D, Shah P. A Critical Review of Non-carious Cervical (Wear) Lesions and the Role of Abfraction, Erosion, and Abrasion. $J$ Dent Res. 2006;85(4):306-312.

13. Estefan A, Furnari P, Goldstein G, et al. In vivo correlation of noncarious cervical lesions and occlusal wear. J Prosth Dent. 2005;93(3):221-226.

14. Goldstein R, Curtis J, Farley B. Mouth habits. In: Goldstein R, editor. Aesthetic Dentistry. Barcelona: STM Editores;2003: 621-654.

15. Mandel L. Dental erosion due to wine. JAm Dent Assoc. 2005;136(1):71-5.

16. Calatrava L. Cervical third lesions, treatment alternatives. Venezuelan Dental Act. 1994;32(1):11-8.

17. Watson M. Trevor F. Investigation and treatment of patiens with teeth affected by tooth substance loss: a review. Dental Update. 2000;5(4):175-81. 
18. Craig R. Materials of Restorative Dentistry. 10th ed, Madrid: Editorial Medica Panamericana;1998.

19. Anusavise KJ. Phillips, Science of Dental Materials. (10th ed.) Mexico Mc Graw-Hill Interamericana;2000.
20. Macchi R. Dental Materials. 3rd ed, Buenos Aires: Editorial Médica Panamerican;2002.

21. De Moraes R, Dos Santos Ribeiro D, Klumb M, et al. In vitro toothbrushing abrasion of dental resin composites: packable, microhybrid, nanohybrid and microfilled materials. Brazilian Oral Research. 2008;22(2):112-118. 